\title{
DYNAMIC DETERMINATION OF THE MODULUS OF ELASTICITY OF MARITIME PINE CROSS-LAMINATED PANELS USING VIBRATION METHODS
}

\author{
GIAN FELICE GIACCU ${ }^{1}$, DANIEL MELONI ${ }^{2}$, MONICA VALDÈS $^{2} \&$ MASSIMO FRAGIACOMO $^{3}$ \\ ${ }^{1}$ Department of Architecture, Design and Urban Planning, University of Sassari, Italy \\ ${ }^{2}$ Department of Civil and Environmental Engineering and Architecture, University of Cagliari, Italy \\ ${ }^{3}$ Department of Civil, Construction-Architectural and Environmental Engineering, University of L'Aquila, Italy
}

\begin{abstract}
This paper describes the preliminary results of an ongoing research activity involving Maritime Pine Cross-Laminated Timber (CLT) panels, aimed to exploit the potentialities of this native species of Sardinia. The modulus of elasticity (MOE) is a key parameter for grading wooden products and evaluating the overall mechanical properties of panels. Free Vibration tests can be an effective method to assess the dynamic MOE of wooden products; the method is based on the direct measurement of the first vibration mode frequency of the specimens and the indirect determination of the elastic parameters. The present work shows a straightforward approach to evaluate the dynamic MOE of cross-laminated panels by choosing suitable boundary conditions depending on the specimen sizes. For this purpose, various experimental tests were conducted on different configurations aiming to evaluate the dynamic MOE for the considered cases. Furthermore, the relationship between global vibrational behaviour of panels and original boards MOE has been investigated. The dynamic MOE obtained by vibration testing method has been compared with the static MOE evaluated by bending tests in order to find a correlation. A linear relationship between dynamic and static MOE was found, with the dynamic MOE being slightly higher than the static MOE, as expected. The dependence of the correlation upon the applied methodology was determined and regression equations were derived and are provided in the paper.

Keywords: cross-laminated timber panels, modulus of elasticity, free vibration methods.
\end{abstract}

\section{INTRODUCTION}

Although Italy does not have a consolidated timber construction tradition as compared to other middle and northern European countries, in the last few years timber structures have gained importance due to sustainability considerations and excellent seismic performance.

Although nowadays most of the timber is imported from abroad, the development of some short production chain programs has started. The aim is to foster the use of local species and exploit the corresponding benefits, which include: increase in the forested land, reduction of hydrogeological hazard, and economical advantages in often underdeveloped areas.

Local lumber species do not always have high mechanical properties but can nevertheless find an effective use in wood-based products like Cross-Laminated Timber (CLT).

Cross-laminated timber panels are wooden structural products consisting of finger jointed boards, arranged crosswise and glued together according to different configurations. The cross-lamination process grants several advantages, including: dimension stability of large and long panels, reduced scatter of original lumber properties, reduced influence of defects, and higher transverse and in-plane rigidity. The Modulus of Elasticity (MOE) plays a fundamental role in the mechanical performances of the panels since various recent studies [1], [2], have shown that the panel MOE is closely related to different mechanical properties [3], [4].

Non-destructive tests have proved to be effective procedures to rapidly assess the performances of the panels [5]. Although in recent years various studies have been carried out on non-destructive evaluation of composite specimens properties [6], [7], limited 
information is available for non-destructive evaluation of mechanical properties of CLT panels. In the present study a non-destructive dynamic approach for assessing mechanical performances of the specimens is proposed, aiming to evaluate the modulus of elasticity of CLT panels.

\section{THEORETICAL BASIS}

Dynamic tests are based on free vibration theory, which allows the determination of MOE through the measurement of first vibration mode of specimens. In this experimental program two different panel configurations were analyzed depending on the size of the considered specimens. A "free-free" support condition has been investigated for the $120 \mathrm{CF}$ panel typology (length $\times$ width $\times$ height) of $4560 \mathrm{~mm} \times 240 \mathrm{~mm} \times 120 \mathrm{~mm}$, while a cantilever configuration has been considered for the $60 \mathrm{PF}$ specimen typology (length $\times$ width $\times$ height) of $1280 \mathrm{~mm} \times 240 \mathrm{~mm} \times 60 \mathrm{~mm}$.

Dynamic MOE has been calculated for the "free-free" configuration using eqn (1), [8].

$$
E_{d}=\frac{f^{2} M L^{3}}{12.65 I}
$$

For the cantilever configuration dynamic MOE has been calculated through the following formula [8].

$$
E_{d}=(2 \pi f)^{2} \frac{M}{L I}\left(\frac{l}{1.875}\right)^{4},
$$

where $E_{d}$ represents the dynamic MOE of the panel $(\mathrm{Pa})$ for the two different configurations, $f$ is the first natural frequency $(\mathrm{Hz}), M$ is the weight of the specimen $(\mathrm{kg} f), L$ is the length of the panel, $I$ is the moment of inertia of the considered cross section $\left(\mathrm{m}^{4}\right)$ and, for the second configuration, $l$ represents the effective span of the cantilever.

In order to make a direct comparison between static and dynamic MOE, static bending tests have been performed for the same specimens, in order to evaluate the static MOE of the CLT panels.

\section{MATERIALS AND METHOD}

\subsection{Materials}

CLT panels are composed by at least three layers of solid timber finger-jointed boards, previously graded, crosswise packed (usually $0^{\circ}-90^{\circ}$ angles) and glued together. For this study a total of 21 3-layered CLT panels made of Sardinian Maritime Pine (Pinus Pinaster) were used. Panels were made using Maritime Pine boards classified, according to UNI EN 338 [9], strength classes, as $\mathrm{C} 16$ and $\mathrm{C} 14$ for the outer and the inner layers respectively. Classification is based on the visual grading rule recently developed by the Department of Civil, Environmental Engineering and Architecture (DICAAR) of the University of Cagliari in cooperation with the CNR-IVALSA of Florence [10], [11]. Seven panels were made of $40 \mathrm{~mm}$ thick boards (120CF series) and 14 panels were made of $20 \mathrm{~mm}$ thick boards (60PF series), for a global panel thickness of $120 \mathrm{~mm}$ and $60 \mathrm{~mm}$ respectively. Main panel geometrical features are reported in Table 1. Mechanical properties of the boards have been previously evaluated by means of bending test performed in accordance to EN 384 [12]. The obtained mean values of module of elasticity parallel to grain $\left(\mathrm{E}_{0, \text { mean }}\right)$ are $7160 \mathrm{MPa}$ and 5190MPa respectively for $120 \mathrm{CF}$ and $60 \mathrm{PF}$ series.

The experimental program was developed at the Laboratory of the DICAAR of the University of Cagliari. 
Table 1: Specification of cross-laminated specimens.

\begin{tabular}{|c|c|c|c|}
\hline $\begin{array}{c}\text { Specimen } \\
\text { code }\end{array}$ & $\begin{array}{c}\text { Number } \\
\text { of } \\
\text { specimens }\end{array}$ & $\begin{array}{c}\text { Specimen size } \\
\text { (length } \times \text { width } \\
\text { thickness, mm) }\end{array}$ & $\begin{array}{c}\text { Average } \\
\text { weight } \\
(\mathrm{kg})\end{array}$ \\
\hline $120 \mathrm{CF}$ & 7 & $4560 \times 240 \times 120$ & 62.40 \\
\hline $60 \mathrm{PF}$ & 14 & $1280 \times 240 \times 60$ & 9.06 \\
\hline
\end{tabular}

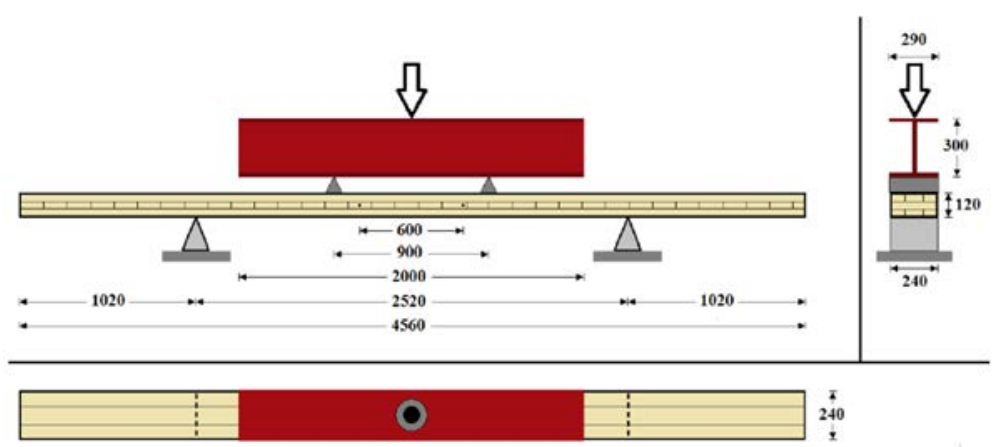

(a)

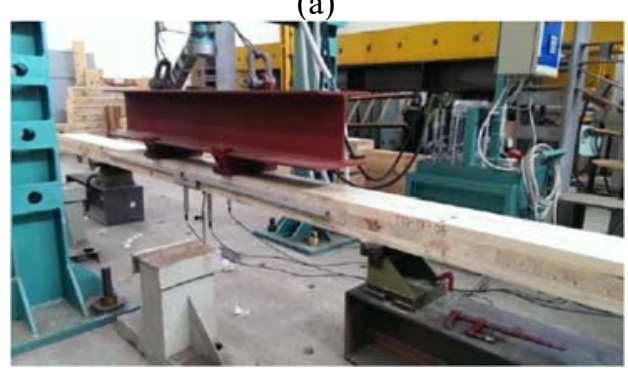

(b)

Figure 1: Testing apparatus for assessing static modulus of elasticity for $120 \mathrm{CF}$ specimens in bending for free-free support conditions. (a) Schematic static test; (b) Laboratory set-up.

\subsection{Static bending test}

Two different experimental setups were arranged in order to evaluate the static modulus of elasticity of the panels, depending on the specimen length to height ratio: a free-free supported configuration and a cantilever configuration.

Moisture content was measured on each panel before the tests has been performed. Thus, the tested specimens parameters were referred to the average moisture content of $12 \%$.

\subsubsection{Free-free supported configuration}

Static bending tests were carried out on panels belonging to the $120 \mathrm{CF}$ series according to the European Standard EN 408 [13], in four-point bending with a span to depth ratio equal to 18 , as shown in Fig. 1. 
A testing machine under displacement control having capacity of $300 \mathrm{kN}$ and a maximum displacement of $300 \mathrm{~mm}$ was used.

Loads were applied at the third points of the span by means of a steel beam positioned on two rollers acting on the panel extrados. Two steel plates $(300 \mathrm{~mm} \times 100 \mathrm{~mm})$ have been interposed between rollers and specimen surface, in order to allow deflection in the panel without significant friction (Fig. 1).

The supports of the rollers at the two ends of the panel allowed the element to move horizontally; local indentations and lateral torsional buckling effects were properly prevented.

According to EN 408 the loading-rate has been set to $4 \mathrm{~mm} / \mathrm{min}$. Vertical displacements were measured by means of LDTs (Linear Displacement Transducers) located on both sides at the neutral axis level, and in the middle of a central gauge length of five times the section thickness (Fig. 1).

The elements were loaded at a low loading level and then unloaded. Local deformations and static modulus of elasticity were calculated according to EN 408 [13].

\subsubsection{Cantilever configuration}

Static cantilever bending tests were performed on 60PF series panels (Fig. 2). The specimens were carefully clamped on a rigid support for a length of $230 \mathrm{~mm}$, while free length was $1050 \mathrm{~mm}$. Displacements of the clamped section were carefully monitored during the test in order to check the effectiveness of the restraint.

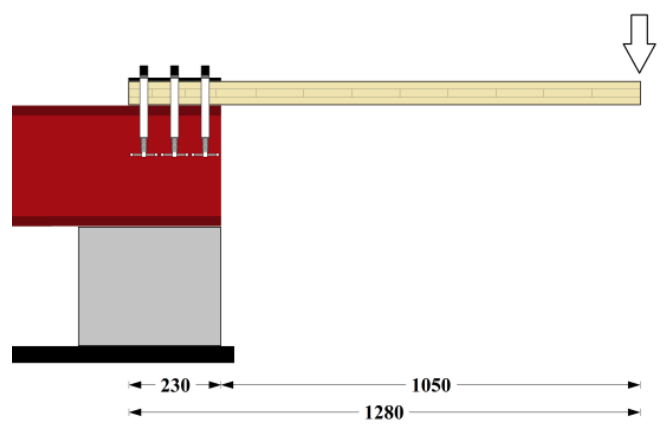

(a)

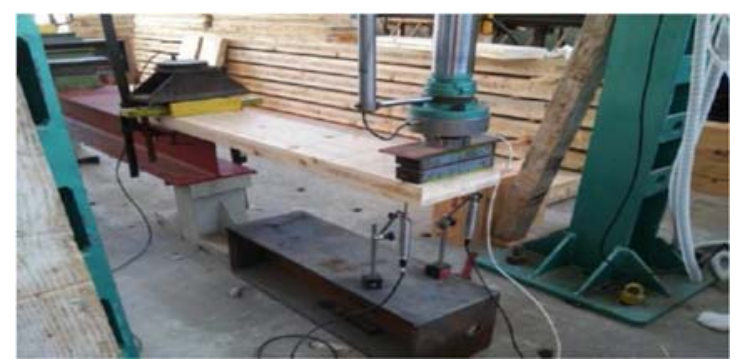

(b)

Figure 2: Testing apparatus for assessing static modulus of elasticity for 60PF specimens in bending for cantilever support conditions. (a) Schematic static test; (b) Laboratory set-up. 
Static loads were applied on the free end of the cantilever beam specimens, according to the procedure described in the previous section; any lateral torsional buckling was avoided by a suitable arrangement (Fig. 2). Vertical deflections were measured by means of a couple of LDTs symmetrically positioned at the bottom of the free end of the panel.

\subsection{Dynamic test}

A vibration test equipment has been developed for evaluating the dynamic MOE of the specimens. A LabVIEW based software has been studied to process vibrations signals and calculate MOE according to eqns (1), (2).

A similar configuration utilized for the static bending test has been used for the dynamic investigation, where testing apparatus was adapted depending on the specimen size.

The first testing apparatus used for the 120CF specimens consisted of two supporting rods used to provide a linear support on the nodal lines of the panel, as shown in Fig. 3. Four accelerometers were then located on the specimen aiming to capture the first vibration frequency of the panel.

The second testing apparatus has been employed for short panels (60PF), where a cantilever configuration has been adopted in order to reduce shear deformation influence on the overall response of the panel, as shown in Fig. 4.

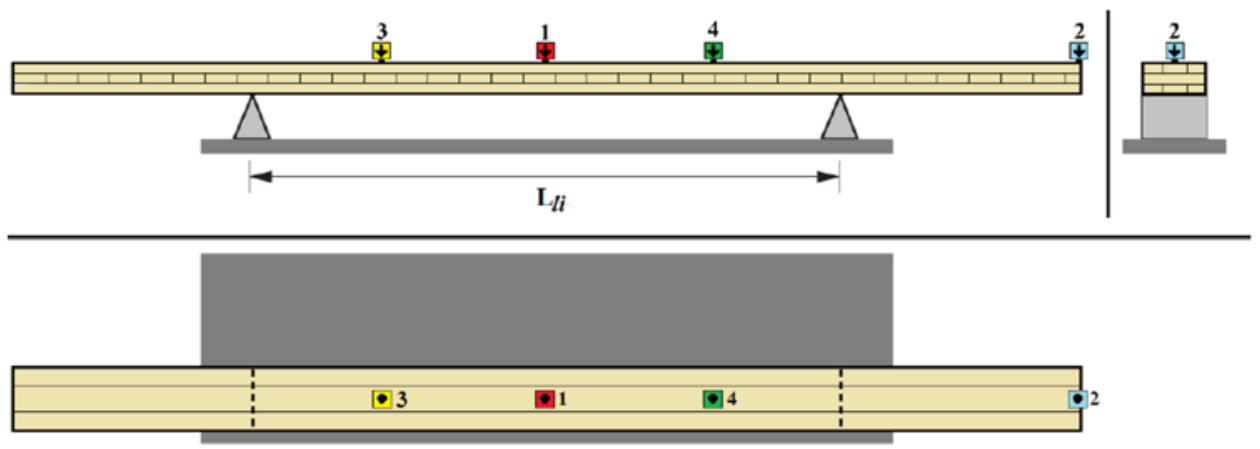

(a)

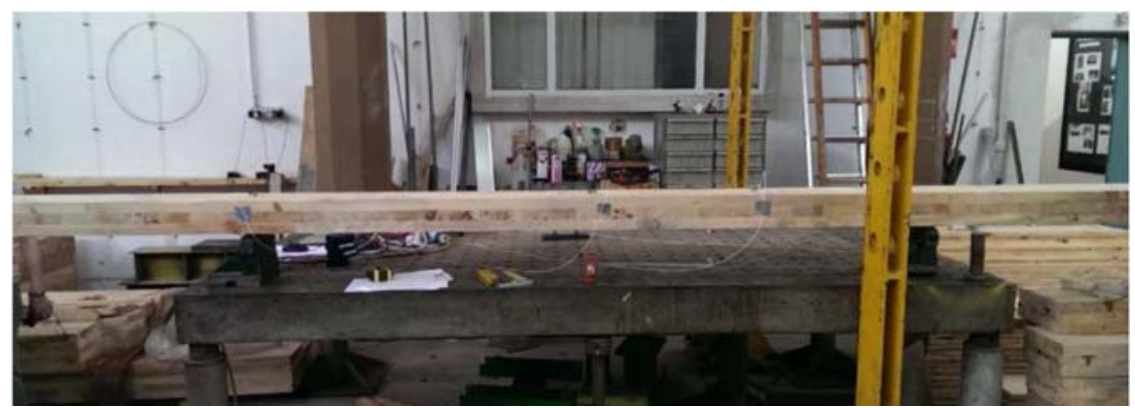

(b)

Figure 3: Testing apparatus for assessing dynamic modulus of elasticity for 120CF specimens in bending for free-free support conditions. (a) Schematic test; (b) Laboratory set-up. 


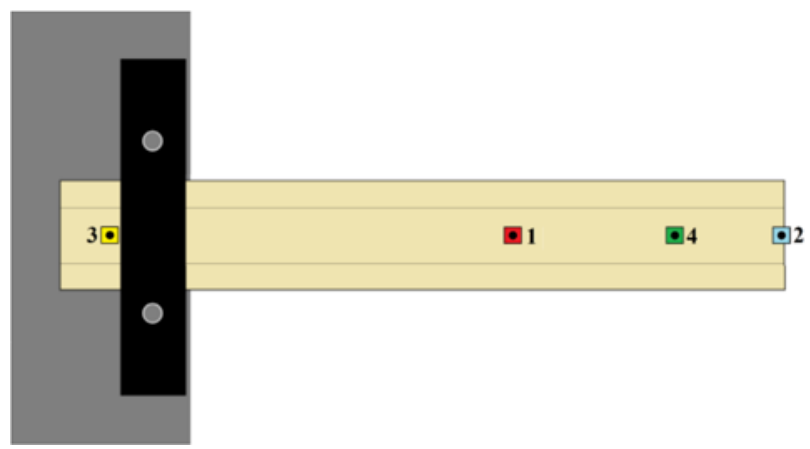

(a)

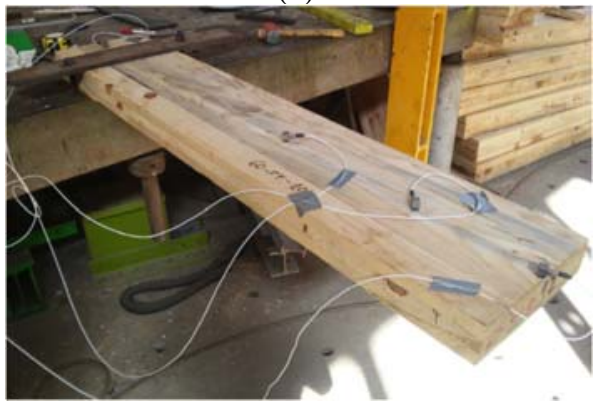

(b)

Figure 4: Testing apparatus for assessing dynamic modulus of elasticity for 60PF specimens in bending for cantilever support conditions. (a) Schematic test; (b) Laboratory set-up.

In all of above described configurations a suitable impulsive mechanical load has been applied to the specimens, aiming to excite the first vibration mode. Vibration accelerations have been detected by a set of accelerometers located in proper positions on the specimen as shown in Fig. 3 and Fig. 4. The signal is detected by the accelerometers through a data acquisition card and processed through the LabVIEW software to directly obtain the first natural frequency of the panel.

\section{RESULTS AND DISCUSSION}

In the present paper static and dynamic MOE were evaluated for 21 specimens of Maritime Pine Cross-Laminated Timber Panels. A direct comparison between static and dynamic MOE has been made, aiming at estimating a relationship between these parameters and to explore the possibility of using non-destructive and quick dynamic tests in substitution of the static ones. In this respect, free vibration method has proved to be a useful methodology to assess in a straightforward way dynamic and consequently static MOE of the cross-laminated panels. As shown in previous works [14], [15], this methodology can be considered a powerful approach to be used for a quality control procedure of CLT products. In the present case dynamic response of the panels specimens were evaluated through a set of accelerometers suitably placed on the specimens. Alternatively a faster and more effective data acquisition system based on laser sensor devices could be considered for a quality control procedure [15]. 


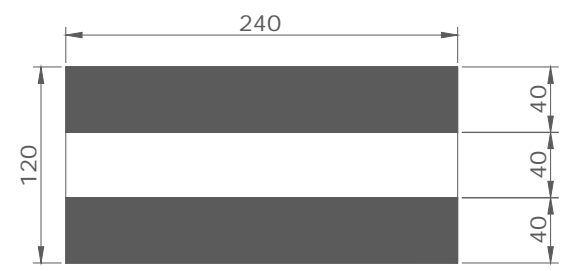

$120 \mathrm{CF}$

(a)

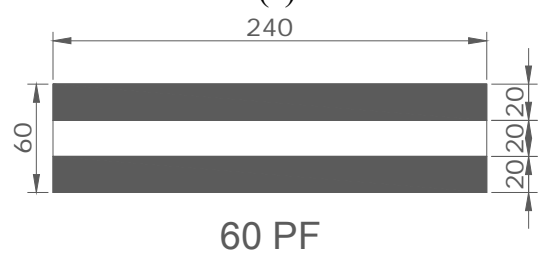

(b)

Figure 5: Cross section features of (a) 120CF specimens; (b) 60PF specimens.

A direct comparison between static and dynamic MOE is shown in this section. Two different approaches were considered for assessing elastic properties of the specimens: the first takes into account the overall cross section of the panel with a moment of inertia evaluated as $I=b h^{3} / 12$, thus the MOE evaluated according to this approach will be named in the following as "Panel MOE"; the second evaluates a simplified effective moment of inertia, accounting only for the outer layers with $0^{\circ}$ grain direction. This second MOE value is expected to be the one of the boards (coloured hatched layers of Fig. 5), therefore it will be named in the following "material MOE".

\subsection{Relationship between dynamic and static panel MOE}

Results of static and dynamic MOE tested on 120CF specimens are reported in Fig. 6(a), where dynamic MOE of the panels has been represented as function of the static MOE. A linear regression has been performed and depicted, with a high correlation co-efficient $\mathrm{R}=0.97\left(\mathrm{R}^{2}=0.94\right)$. A similar correlation can be observed in Fig. 6(b) for 60PF cantilever specimens, where still a high correlation coefficient $R=0.95\left(R^{2}=0.91\right)$ characterizes the regression analysis. These results clearly confirm the effectiveness of the proposed non-destructive dynamic approach for the assessment of panel MOE and therefore the overall mechanical performance of the panel; the MOE can be provided to designers and constructors by the producer in technical data sheets.

\subsection{Relationship between dynamic and static material MOE}

Fig. 7 shows similar results in terms of material MOE. Both for 120CF (Fig. 7(a)) and 60PF (Fig. 7(b)), dynamic and static MOE are correlated again by means of a linear regression analysis, which, as expected, is almost the same of the one previously discussed. This time the analysis deals with the material MOE, i.e. longitudinal modulus of elasticity in the grain direction of the upper and lower boards (C16 grade), with the approximation given by effective moment of inertia formulation discussed at the beginning of this section, that neglects the contribution of the central (C14 grade) $90^{\circ}$ layer. 
578 Sustainable Development and Planning IX

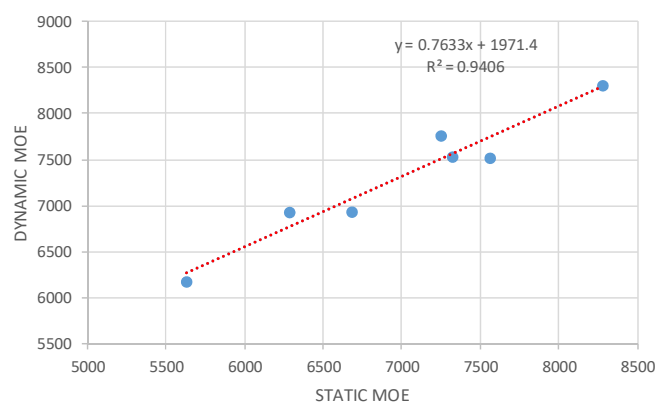

(a)

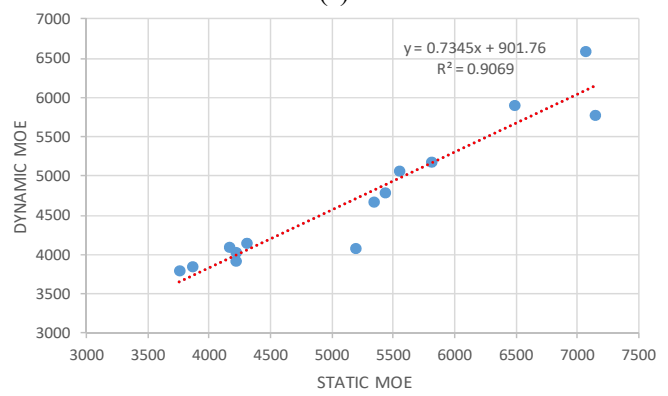

(b)

Figure 6: Relationship between static and dynamic panel MOE. (a) 120CF; (b) 60PF.

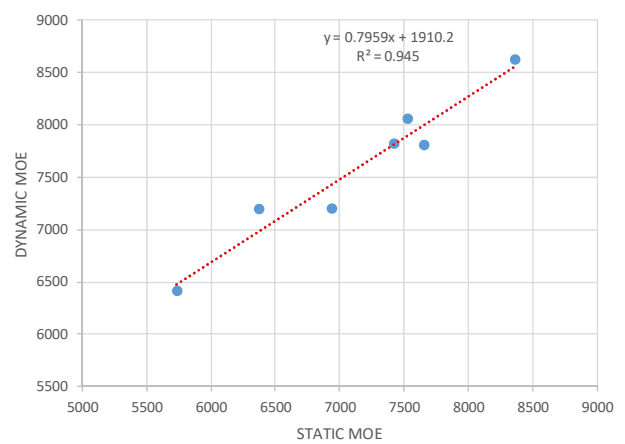

(a)

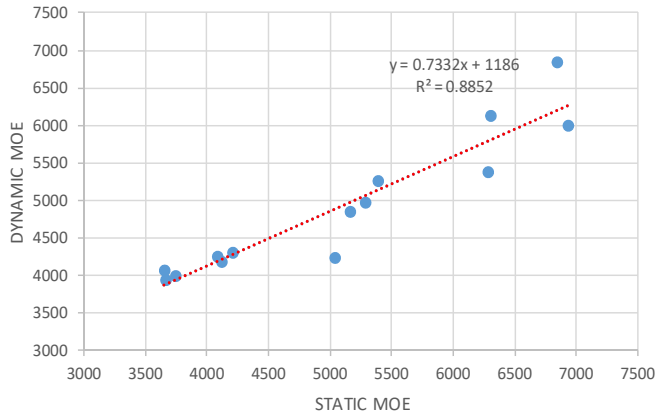

(b)

Figure 7: Relationship between static and dynamic boards MOE. (a) 120CF; (b) 60PF. 
Mean values of material MOE shown in previous figures are $7140 \mathrm{MPa}$ and $5050 \mathrm{MPa}$ respectively for $120 \mathrm{CF}$ and $60 \mathrm{PFseries,}$ which satisfactorily match the values reported in Section 3.1, based on board flexural tests, proving the effectiveness of the discussed analysis. This second approach can be useful for panel structural design usually stemming from board mechanical properties.

\section{ACKNOWLEDGEMENT}

The authors would like to thank the financial support of Regione Autonoma della Sardegna (L.R.7 agosto 2007, N.7: "Promozione della Ricerca Scientifica e dell'Innovazione Tecnologica in Sardegna”).

\section{REFERENCES}

[1] Leban, J.M., Haines, D.W. \& Herbé, C., Determination of Young'modulus for spruce, fir and isotropic materials by the resonance flexure method with comparisons to static flexure and other dynamic methods. Wood Sci. Technol, 30, pp. 253-263, 1996.

[2] Chi, D., Tong, X., Lin, X., Dynamic detection for Young's modules and bend strength of fibreboard. Wood Process. Mach, 17(5), pp. 14-17, 2006.

[3] Movchan, A.B., Brun, M., Slepyan, L.I. \& Giaccu, G.F., Dynamic multi-structure in modelling a transition flexural wave. Mathematika, 61 (2), pp. 444-456, 2015.

[4] Carta, G., Giaccu, G.F. \& Brun, M., A phononic band gap model for long bridges. The 'Brabau' bridge case. Engineering Structures, 140, pp. 66-76, 2017.

[5] Concu, G., de Nicolo, B., Trulli, N., Valdés, M. \& Fragiacomo, M., Strength class prediction of Sardinia grown timber by means of non destructive parameters. Advanced Materials Research, 778, pp. 191-198, 2013.

[6] Moslemi, A.A., Dynamic viscoelasticity in hardboard. Forest Products Journal, 17(1) pp. 25-33, 1967.

[7] Zhou, H.B., Ren, H.Q, Fei, B.H. \& Jiang, Z.H., Dynamical test on flexural and shear modulus of composite wood panels. Journal of Building Materials, 10(5) pp. 561-565, 2007.

[8] Meirovitch, L., Analytical methods in vibrations, The Macmillan Company: New York, pp. 161-166, 1967.

[9] UNI EN 338. 2009. Structural Timber: Class Strength.

[10] Riu, R., Caratterizzazione di pannelli x-lam in pino marittimo sardo. $\mathrm{PhD}$ thesis, University of Cagliari, Italy, 2016.

[11] Concu, G., Fragiacomo, M., Trulli, N. \& Valdes, M., Grading of Maritime Pine from Sardinia (Italy) for use in cross-laminated timber. Proceedings of the Institution of Civil Engineers - Construction Materials, 2017.

[12] EN 384: 2016. Structural timber. Determination of characteristic values of mechanical properties and density.

[13] UNI EN 408. 2010. Timber structures Structural timber and glued laminated timber. Determination of some physical and mechanical properties.

[14] Guan, C., Zhang, H., Hunt, J.F. \& Yan, H., Determining shear modulus of thin wood composite materials using a cantilever beam vibration method. Construction and Building Materials, 121, pp. 285-289, 2016.

[15] Guan, C., Zhang, H., Zhou, L. \& Wang, H., Dynamic determination of modulus of elasticity of full-size wood composite panels using a vibration method. Construction and Building Materials, 100, pp. 201-206, 2015. 